\title{
Art History Research in the Digital Humanistic Era: Paradigm Shift and Method Transformation
}

\author{
Niu Xuyu ${ }^{1}$

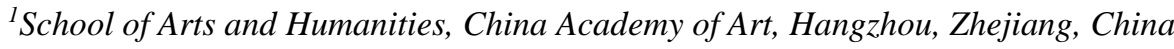 \\ *Corresponding author.Email: niu_xuyu@163.com
}

\begin{abstract}
This article will make a comprehensive summary, generalization and refinement of the academic research focus and academic research methods of "digital humanities". Digital humanities does not have a clear definition, but it emphasizes the combination of digital technology and traditional humanities. The current digital humanities research generally includes method research, meaning research, art history and digital humanities interactive research.

Digital humanities make art history research methods more systematic and complete, make literature research more convenient, make interdisciplinary research methods gradually generalized, and new research methods such as quantitative research are derived.

If we want to truly construct a complete "digital humanities" research, we need to support it in terms of talent training and national policies and so on. As a new trend of research, digital humanities may cause the loss of research methods, which requires our attention and reflection.
\end{abstract}

Keywords: Digital Humanities, Art History Research, Overview of Research Status, Paradigm Shift, Method Transformation

\section{RESEARCH OVERVIEW OF "DIGITAL HUMANITIES" IN THE ERA OF DIGITAL HUMANITIES}

\subsection{Definition and Characteristics of "Digital Humanities"}

At the moment, we have entered the global information age. Following this, the vigorous development of digital technologies such as new media technology, computer technology and network technology has provided sufficient preconditions for digital humanities research. A set of technologies and methods represented by computers has given birth to the transformation of academic research approaches, methods and styles.

We can say without evasiveness that the field of humanities and social sciences is or will undergo a major change. Digital and system related research will become a hot word in academic research and art history research.

In this context, "digital humanities" as a research method and research object began to appear in our field of vision. In the Western academic circles, the field of digital humanities has been very extensive, but as an emerging research with frequent development and changes, "digital humanities" has not yet been recognized and clearly defined in China (The American Modern Language Association came forward to organize an open online discussion. Since 2009, the text of the discussion has been edited into a book. Two volumes were published in 2012 and 2016. The title of the book is "Debates in the Digital Humanities", the book defines more than twenty kinds of digital humanities, but none of them are completely satisfactory. ) : Li Dian believes that "digital humanities is using digital media tools and methods to reexamine traditional humanities subjects, and at the same time use humanities research paradigms and methods to explore the functions and significance of digital media." [1]; Meng Jian and Hu Xuefeng also believe that digital humanities is not a simple application of digital technology in the humanities, but a media-driven transformation of academic production methods [2]. Feng Baifan broadly defines digital humanities as "a considerable improvement of the original research field of humanities by means of digital or computing technology". [3]Chen Jing affirmed the importance of digital humanities and believed that digital humanities is "a new path for the development of humanities and academics in a new technological development ecological 
environment...a paradigm of the inevitable transformation of digital production" [4].

In general, the current understanding of digital humanities can be roughly divided into four categories: one is to regard it as a research method, that is, to use digital information and computers as tools to solve problems in traditional humanities; The second is to regard it as an interdisciplinary and intermedia research field; The third is to establish it as a discipline. Many Western universities have established relevant education systems and institutions and incorporated them into university courses; The fourth is to regard it as a practice, a form of academic organization and practical activities using an interdisciplinary model [2]

Regardless of how various scholars define digital humanities, we can summarize the core common points from these disputes, that is, emphasizing the integration of digital technology and traditional humanities. This is a derivative of technological development in the current era and provides new research methods and perspectives for humanities research.

\subsection{Current status of "digital humanities" research at home and abroad}

The same is true for foreign research on digital humanities, numerous and complex. Since the 1960s, Western academic circles have begun to discuss "how humanists can reconstruct a knowledge system in the social context of changed information methods, and explore how people as subjects perceive, think, and disseminate knowledge from the perspectives of information technology, media, new media, and digital media" [4]. In the past 20 years, digital humanities have risen rapidly and have a wide-ranging influence worldwide [2]. At present, many digital humanities research centers have been established abroad, such as the Humanities Laboratory of Stanford University and the Digital Humanities Research Center of the University of Southern California. In addition, two major digital humanities research alliances have been formed internationally, namely The Alliance of Digital Humanities Organizations (ADHO) and the Digital Humanities Center Network. At the same time, a number of digital humanities journals have been established, such as Digital Studies, Digital Humanities Quarterly (DHQ), etc.

\subsubsection{Several general aspects of the study of digital humanities}

One is the significance of digital humanities research. Chen Jing's "Current Status and Significance of 'Digital Humanities' Research in China" and "History and Controversy: Overview of the Development of 'Digital Humanities' in the United Kingdom and the United States" respectively systematically reviewed the status of digital humanities research in China and the West, and explained its research value and significance of future knowledge system and method construction; Meng Jian and $\mathrm{Hu}$ Xuefeng's "Digital Humanities: Media-Driven Reform of Academic Production Mode" treats digital humanities from a media perspective, and considers it to be a thorough media-driven revolution in academic production.

The second is the method of digital humanities research. Li Dian, "The 'Digital Turn' of the Humanities in the Post-Theoretical Era" proposed the "methodological revolution" of the digital humanities in the "post-theoretical" era; Su Fangli, Chang Renjie, "Digital Humanities Research--Interdisciplinary, Collaborative Models and Themes" uses co-occurrence data between disciplines related to digital humanities research to analyze the pattern and development of interdisciplinary networks, as well as similarities and differences of research topics in various discipline communities. This promotes more effective cooperation among various disciplines connected by digital humanities research.

The third is the intersection of digital humanities and art history research. Feng Baifan's article "Improvement or Subversion: Research on Digital Humanities and Art History" explains how digital humanities help traditional art history avoid subjective assumptions as much as possible, and achieve the effectiveness and objectivity of research results; Fan Zhen's "Machine Reading 'The Autobiography of the Old Man Baishi'--A Preliminary Study on the Digital Humanities Research Method of Art History" uses the relevant tools of computer natural language processing to perform word frequency statistics, high-frequency distribution and close reading of the semantic network to determine the core content of "Autobiography of the Old Man Baishi", which is a powerful practice combining art history and digital humanities research methods; Chen Liang put forward the concept of "digital art history" in "Digital Humanities and Digital Art History", and analyzed its two aspects: Digitization of art history text database and image database and data processing in art history research; Claire Bishop's "Methods and Approaches-A Critique of 'Digital Art History'" and Lu Yuemi's "Constructing the Humanistic Spirit in the Development of Digital Art" carried out a reflection and criticism of the combination of digital humanities and art history. In addition, many scholars' research also involves the intersection of digital humanities and film art history (such as Han Tingting, Li Daoxin), literature (such as Li Tian) and art education (such as Jiang Keyu), and I will not list them here.

\subsubsection{Significant influence of domestic "digital humanities"}

Domestic research on digital humanities seems to have just started, but it has already shown signs: In 2011, 
Wuhan University established China's first digital humanities research center ( "Digital Humanities Research Center of Wuhan University", http://dh.whu.edu.cn/dh/web/index.html ) . In 2012, National Taiwan University formally established the "Digital Humanities Research Center" ( National Taiwan University Digital Humanities Research Center", http://digital.ntu.edu.tw/introduction.jsp ) , etc. All assist the development of digital humanities research institutionally. Correspondingly, in the past ten years, projects on digital humanities research have been promoted, such as the "Chinese History Biography Database" (CBDB) jointly developed by Harvard University, Taiwan's "Academic Research Institute" and Peking University. Many national social science fund projects fund scholars to build various thematic databases and provide digital resources for humanities scholars. In addition, the literature on digital humanities research is also constantly published. The "Digital Humanities and Qing History Research" series of lectures redefine, interpret, and increase the thinking of Qing history research from the perspective of digital humanities. As well as the research of scholars such as Chen Jing, Meng Jian, Hu Xuefeng, etc., they have laid the methodological foundation in the field of digital humanities, expanded the cross-disciplinary vision of humanities scholars, and opened the way for the future development of digital humanities in China.

\section{RESEARCH METHOD INNOVATION AND RESEARCH PARADIGM TRANSFORMATION BROUGHT ABOUT BY THE INTERSECTION OF " DIGITAL HUMANITIES " AND ART HISTORY RESEARCH}

\subsection{Facilitation of research approaches: the digitization of research images and research texts}

Nowadays, some art historians use various digital information processing equipment to digitize traditional art works and documents, and realize the transformation of the form of art history research materials based on digital humanities. While art history research images and documents have gained new carriers through digital technology, they have also facilitated art history research approaches.

In the era of printing knowledge production in the past, the text and image data of art history research were collected on paper carriers, which not only took up storage space and was inconvenient to organize, but it also took extremely high time and cost to search for documents in a huge collection of books. The digital humanities method has largely solved the series of problems related to paper documents: Through the collation of digital libraries and other technical institutions, the images, texts, metadata and other information are digitized, and relevant documents can be established in their own databases. The relevant images are stored in the form of electronic images in the gallery, making it easy to copy and disseminate. For example, the Rossetti Archive is dedicated to collecting all the relevant archives of the British painter and poet Rossetti; The digital Dunhuang website can realize the ideal state of viewing the Dunhuang grottoes without leaving home; Most of the entries in the German Art History Encyclopedia are available on the Internet. Art historians can search for massive amounts of materials and highdefinition digital images in a short time only through the retrieval system, which greatly improves the research efficiency.

In addition, many communication media and platforms (mainly web) spawned by digital technology provide a large-scale and multi-field communication mode for academic research. Through the resource sharing of computer networks, the degree of discussion and interaction among art historians has deepened. The collision, friction and blending of different academic viewpoints is conducive to the formation of a more inclusive and cooperative academic atmosphere.

\subsection{Derivation of cross-media research methods: cross-disciplinary research supported by digital systems}

With the support of digital humanities, the research method of art history has changed from the previous single-media research to the current cross-media research. The use of digital humanities methods allows us not only to easily obtain related classic texts, but also to pay attention to non-classical texts, namely the method of combining "distant reading" and "close reading" proposed by Franco Moretti. The so-called "distant reading" is actually the use of big data analysis methods, ignoring some details, and analyzing and grasping art history from a more macro perspective. Not only that, in addition to traditional paper paintings and books and documents, historical materials can also exist in rich forms such as video and audio, and the collection and preservation of these materials cannot be separated from the support of digital technology.

Secondly, digital humanities have the function of "spatial restoration". When art history research experts want to conduct in-depth research and analysis on a certain art work, they can use digital technology to combine geographic information systems with art history research. Using digital humanities technology, it is possible to map the trajectories of artists, works of art and art institutions in a certain time and space to achieve "spatial restoration", thereby discovering new research perspectives and models, which are difficult for traditional recording methods. 
After fully studying the works and related factors, the contemporary background and psychology of the artist's creation are also an indispensable part of art history research. With the help of digital humanities, research methods in this field fully reflect the advantages of interdisciplinary research. For example, the analysis and integration advantages of big data have promoted the development of artists' social network analysis. By exploring the relationship between artists and sponsors, collectors, etc., richer research results can be obtained.

In short, unlike paper-based media, electronic media offers more technical possibilities for research. With the support of digital humanities, the art history research of interdisciplinary, intermedia, and interdisciplinary collaboration has been carried out smoothly to a large extent. The comprehensive research of natural sciences, applied engineering, social sciences, humanities and arts is thus opened up, allowing researchers to expand to other fields from their own disciplinary standpoints, and to start from "problem-oriented" research with scholars in other disciplines, thus achieving "the greatest sharing of research resources, the greatest versatility of analysis methods, and the greatest integration of knowledge content" [5]. This may be a revolutionary development in the analytical methods of art history research.

\subsection{The Transformation of the Research on the Audience Acceptance of Art History from the Perspective of Data Analysis and Statistics}

Art history is also the history of art acceptance. Art history emphasizes the active creation of viewers rather than passive acceptance. It is believed that the study of art history should not only objectively analyze works and artists, but also pay attention to the acceptance of art works in different historical periods.

The analysis of art acceptance and audience acceptance psychology will develop more objective and three-dimensional with the help of digital humanities. Before the emergence of digital technology, art historians could only rely on rough statistics (such as the sales of works) or even subjective assumptions to make judgments on audience acceptance, and it is difficult to form research results with convincing, consistent time and space level.

However, digital technology, such as digital character modeling, database, etc., performs big data analysis on audience psychology and audience expectations in data analysis and other aspects, such as using data to count the number of exhibitions, the number of participants, the price of works, related data on auctions, and website clicks, etc., and by building digital models, it is possible to analyze the changes in the aesthetics of the audience in the art history, which greatly increases the objectivity and credibility of art history research..

\subsection{Quantitative Analysis and "Quantitative Research" of Art History}

In recent years, the bibliometric analysis method has been widely used in the field of academic research. This method is a research method based on bibliometrics and considering literature information as the research object. This method emphasizes the use of mathematics and statistics to examine the external characteristics of the literature, so as to describe, evaluate and predict the research status and development trend of a certain academic field [6].

Therefore, the quantitative analysis method is also applicable to the field of art history research. It carries out quantitative analysis and analytical analysis of art works, and reviews its quantitative content according to a system to summarize the value of the text.

In terms of research methods, this method of measurement and division will help refine the text research and highlight the content of the text. This type of quantitative analysis has formed the basic criteria for judging the quality of artworks, and has played a huge role in practicability and objectivity. For example, it is convenient to evaluate the grades when evaluating students' works, which can be used as a basis for scoring, which can be applied to art examination review and basic teaching; It can show the general development trend and research status of art history more objectively.

However, in the more advanced field of art, this method of digitizing and symbolizing human imagination has stifled artistic creativity to a certain extent. The works of very individual artists such as Van Gogh will be worthless under the systematic scoring of this analytical method. This is also the drawback and reflection of the use of digital humanistic methods in art history research.

Therefore, not all art and humanities scholars need to master quantitative analysis and text calculation methods, but they should also understand these methods, learn systematic and clear methods, expand their academic horizons, and be able to correctly evaluate them.

\section{THE FUTURE OF DIGITAL HUMANITIES: REFLECTIONS AND SUGGESTIONS ON THE ART HISTORY OF DIGITAL HUMANITIES RESEARCH}

\subsection{The lack of interdisciplinary talent training}

Nowadays, our research talents are not enough for the combination of digital humanities and art history.

In terms of the construction of the discipline of art history, the cultivation of talents pays more attention to professionalism and artistry, rather than taking interdisciplinary art history as the training and education goal. The disciplinary boundaries between art history 
majors and technical majors in various universities are usually very clear, with strong discipline orientation, different education, knowledge and assessment systems, and it is difficult to train interdisciplinary and multidisciplinary talents.

Therefore, the professional high-level art history researchers cultivated by this basic discipline construction model rarely have interdisciplinary thinking, and it is difficult to form an open vision of the combination of digital humanities and art history. Correspondingly, the current resource allocation and various supporting policies are mostly based on majors or departments, and it is difficult to obtain funding for interdisciplinary research projects. Therefore, it is urgent to promote interdisciplinary art history research methods under the digital humanistic framework.

One is that the arts and humanities need to strengthen the "practicality" of digital humanities. The concept of a broad digital humanities practitioner put forward by Western scholar Stephen Ramsay is worth learning from.

(Stephen Ramsay, Geoffrey Rockwell, "Developing Things: Notes toward an Epistemology of Building in the Digital Humanities", Debates in Digital Humanities, University Of Minnesota Press, the online access link: http://dhdebates.gc.cuny.edu/debates/text/11, 2012. ) It generalizes the scope of "digital" to include not only technical programming languages, but also the use of databases and R\&D software for humanities research. This requires art history scholars to not only use digital humanities technology for humanistic knowledge dissemination and management, but also to intervene in the practice of scientific research and development technology to become a new type of art history talent combining digital technology and humanistic knowledge research capabilities.

Second, art historians should make full use of the conditions of the times. It is necessary to fully integrate art humanities with digital humanities, promote the scientific development of art history with scientific objectivity and authenticity, solve the digital problem of art history in the new era, expand the depth and breadth of art history research, and adapt it to digitalization trends and promote the transformation of its new knowledge production paradigm.

\subsection{Difficulties in the construction of digital systems}

In order to use digital humanistic methods in art history research, the digital system constructed by professionals must be the technical support. However, the construction of my China's digital system is facing multiple difficulties.

First, there is insufficient high-tech talents needed to construct a digital system. The late start of digital humanities research in China, coupled with the particularity of Chinese characters (many mature text digitization software is based on English and other Latin alphabet languages), and the long time required to train talents have led many researchers' cognition of digital technology such as databases, Internet, and word processing software to be not deep enough, and it is only used as a research tool, "and there is still a lack of cognition and critical reflection on the deep operation mechanism, technical principles, logical methods, ideology, and ethical issues inherent in technology"[4] Therefore, in the future cultivation of innovative talents, we should focus on cultivating scholars' "awareness of academic issues" rather than "awareness of technology orientation." In this way, in the construction of the digital humanistic system of art history, high-tech talents can play the correct guiding role, so that the construction of the digital system can adapt to the development trend of art history to the greatest extent and realize the complementarity of the two.

Second, building a digital resource system consumes a lot of time and cost, and is costly and labor-intensive. Today, there are countless historical materials such as art works and documents that can be passed down to the world. It is not possible to digitize them one by one and collect them into the library overnight. It is a vast project that requires and involves a great number of teams. It will be a "future project" that will always require continuous and persevering construction from each generation of us.

In this case, all sectors of society should take measures.

First, the government needs to provide sufficient financial support and policy support for digital humanities related disciplines to ensure the development of digital technology and the cultivation of high-end talents. In recent years, policy dividends such as "Internet+" and "artificial intelligence" that my country has strongly advocated may provide opportunities for the construction of art history digital systems.

The second is to strengthen interdisciplinary cooperation within academia. Technical majors promote the development of science and technology in terms of databases and text analysis. Humanities need to correctly understand the impact of science and technology on human knowledge, carry out critical reflection in terms of ideology, technical principles and ethical issues, so that each uses their own strengths to accelerate the construction of a healthy development of digital systems.

\subsection{Lost research method}

As mentioned above, the current methodological problem of art history research is that it pays too much attention to the instrumental nature of digital technology, rather than digging into its personal nature. Some technologies such as data processing, text analysis, and 
the construction of digital humanities communities have gradually confused the eyes of researchers. A large number of research results are mainly concentrated in information science, computer science, computational linguistics, library science and other technical aspects, while turning to traditional humanities such as history, literature, art, and philosophy do not penetrate deeply.

Therefore, we should avoid "technology-oriented awareness", but establish "awareness of academic issues", starting from the theory of art history development, using digital humanistic technology with a reference attitude, and driving the construction of digital resources with problems, by which we can integrate data to the greatest extent to promote the development of art history.

At the same time, we must pay attention to the importance of practice and look at the emerging research methods of the current era from an inclusive perspective. Art historians should study extensively, practice boldly, choose the best from practical results, and gradually expand and improve the digital humanistic method system of art history.

\subsection{Copyright issues in data acquisition}

Nowadays, the awareness of academic norms and achievement patents is continuously strengthened, and the degree of access to and openness of data resources is also the difficulty in the application of digital humanities in art history research. For example, many digitized ancient Chinese classics are difficult to share resources, but are sold by many digital holders and institutions through business models, and sometimes they are expensive and difficult to afford; Or it is not open to the outside world due to copyright and patent protection, which greatly limits the circulation of academic resources and data, and hinders the ability to collaborate in the academic field.

In this context, some institutions have begun to make certain efforts in resource sharing and openness: Shanghai Library has established and opened a data sharing platform ( "Shanghai Library Open Data Platform", http: / /data.library.sh.cn/) ,"released some data that can be accessed by various institutions and projects in the form of linked data, and launched an application development competition, and opened up its collection of genealogy document information and content information, encouraging participants to use data creatively, thereby maximizing the value of resources" [5]. Similar platforms undoubtedly promote academic exchanges and resource dissemination. In the future with more advanced science and technology and more convenient access to digital information, the trend of resource opening and sharing may gradually expand. Relevant data holders should actively realize their own social responsibilities and help promote the publication and dissemination of research materials.

\section{CONCLUSION}

This article discusses the "digital humanities" research method in the digital age and the paradigm and method transformation that this important method brings to art history research, and proposes reflections and suggestions on this phenomenon. Through a review of previous studies, it can be seen that digital humanities emphasizes the combination of digital technology and traditional humanities. This interdisciplinary combination has brought about the convenience of art history research, promoted the further expansion of interdisciplinary research, brought a more objective statistical method to art history audience research, and created the "quantitative analysis" of art history research.

\section{REFERENCES}

[1] Li Dian. The "digital shift" of the humanities in the post-theoretical era[N]. Journal of Social Sciences, 2017-08-10(005).

[2] Meng Jian, Hu Xuefeng. Digital Humanities: MediaDriven Reform of Academic Production Mode[J]. Modern Communication (Journal of Communication University of China),2019,41(04): $24-28+54$.

[3] Feng Baifan. Improvement or Subversion: Research on Digital Humanities and Art History[J].Picture Magazine,2017(08):54-59.

[4] Chen Jing. Plural Digital Humanities_Chinese Digital Humanities from a Comparative Perspective[J]. Abstracts of Social Sciences,2020(01):104-106.

[5] Chen Jing. Current Status and Significance of "Digital Humanities" Research in China[J].Shandong Social Sciences,2018(07): 5963.

[6] Qiu Junping and Wang Yuefen, Analytic Method of Bibliometric Content, Beijing: National Library Press, 2008. 